\title{
Thermal Load of Multidisc Wet Friction Assemblies at Braking Regime
}

\author{
Zlatomir Živanović1,* - Miodrag Milić 2 \\ ${ }^{1}$ Institute of Nuclear Sciences "VINČA", Serbia \\ 2 Military Technical Institute, Belgrade, Serbia
}

The paper presents the results of thermal load investigations of multidisc friction assemblies used as service brakes of a high speed tracked vehicle. By simulating the corresponding braking regimes and measuring the characteristic quantities on an inertial test stand, the relevant parameters of the braking process have been determined. The obtained results have been analyzed and compared to the permitted values of thermal load of the material of the tested friction discs. After a certain number of braking cycles by visual inspection of the brakes the state of the friction elements have been determined. The speed limits for braking the vehicle at higher transmission gear ratios, which may result in a permanent damage of the brakes, have been determined.

(C)2011 Journal of Mechanical Engineering. All rights reserved.

Keywords: track vehicle, wet friction assembly, thermal load

\section{INTRODUCTION}

The most widespread application of wet multidisc friction assemblies (clutches or brakes) is in motor vehicle transmissions with planetary gears. It is possible to use them in transmissions of high-speed tracked vehicles for the purpose of gear change, in the mechanisms for steering, as the main clutch, and even as the service brake.

Sintered materials are usually applied in multidisc friction assemblies operating in oil, intended for heavy duty working conditions. These materials are obtained by means of the technology of sintering powdered materials whose contents are dominated by certain elements, such as iron or copper. This results in highly wearresistant materials.

In order to establish thermal load wet multidisc friction brakes applied in the transmission of a high-speed tracked vehicle, their performance is investigated by simulating the corresponding regimes of exploitation on a test stand.

On the basis of these tests, after certain number of braking cycles the interdependence between the state of the brake and the regime of sliding is established, i.e. the temperatures of the sliding surfaces are measured.

By correlating the obtained test stand results with the process of braking in real vehicles, the braking regimes (range of speeds) which result in damaging of the brakes can be identified. The obtained data can be reliably applied in practice for the purpose of preserving the operative capabilities of the brakes through observing certain recommendations, i.e. by avoiding critical operating regimes. In this way good operative availability of a vehicle can be provided and the unnecessary high costs of gearbox repairs may be avoided.

\section{CHARACTERISTICS OF THE EXAMINED WET MULTIDISC BRAKES}

Functional elements of the examined wet multidisc brakes are a combination of steel and sintered discs made of metalloceramic friction material MK-5 [1]. This material is a composition of copper powder and different alloying ingredients. The components of MK-5 material are: 62 to $85 \%$ copper, 5 to $10 \%$ tin, 4 to $8 \%$ graphite, 0 to $2 \%$ iron, 0 to $2 \%$ nickel, $0.3 \%$ silicon dioxide, and $0.3 \%$ asbestos [2] and [3].

Linings of the metalloceramic discs are made by compressing the powdered mixture of the above elements which is then sintered and mated with a steel core.

A metalloceramic friction disc, with the corresponding geometric data, is shown in Fig. 1 [4]. Spiral-radial grooves are made on the friction

*Corr. Author's Address: Institute of Nuclear Sciences "VINČA", 11001 Belgrade, Serbia, zzivanovic@vinca.rs 
surface for supplying oil for lubrication, cooling, and draining the products of wear. The effective friction surface is about $60 \%$ of the total disc surface.

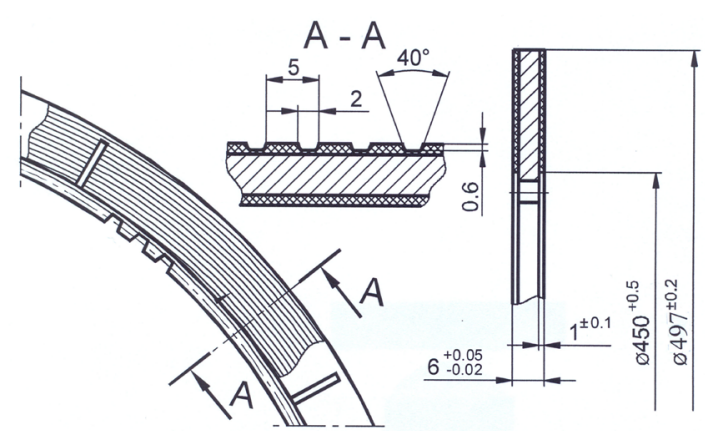

Fig. 1. Geometric data of a sintered friction disc

The wet multidisc brakes, which are the subject of these investigations, consist of a package of the steel and metalloceramic friction discs, separator discs, and the hydraulic cylinders serving for engagement of the brakes by means of oil pressure. The brakes are denoted by $F_{4}$ and $F_{5}$ and their basic characteristics [5] are presented in Table 1, where $z$ is number of friction surfaces, $R_{S}$ is mean radius of friction surface, $A_{l}$ is effective friction surface, $A_{k}$ is effective piston surface of the hydraulic cylinder, $m_{l}$ is average mass of friction discs and $F_{0}$ is force of the return springs.

Table 1. Basic characteristics of the brakes

\begin{tabular}{|c|c|c|c|}
\hline \multicolumn{2}{|c|}{$\begin{array}{c}\text { Basic } \\
\text { characteristics }\end{array}$} & \multicolumn{2}{|c|}{ Brake } \\
\cline { 2 - 4 } & - & $F_{4}$ & $F_{5}$ \\
\hline$z$ & - & 10 & 12 \\
\hline$R_{S}$ & {$[\mathrm{~m}]$} & \multicolumn{2}{|c|}{0.237} \\
\hline$A_{l}$ & {$\left[\times 10^{-4} \mathrm{~m}^{2}\right]$} & \multicolumn{2}{|c|}{220} \\
\hline$m_{l}$ & {$[\mathrm{~kg}]$} & \multicolumn{2}{|c|}{1.465} \\
\hline$A_{k}$ & {$\left[\times 10^{-4} \mathrm{~m}^{2}\right]$} & \multicolumn{2}{|c|}{380} \\
\hline$F_{0}$ & {$[\mathrm{~N}]$} & 2340 & 2700 \\
\hline
\end{tabular}

Brakes $F_{4}$ and $F_{5}$ are constituent parts of both planetary gearboxes used in the transmission of a high-speed tracked vehicle.

\section{THERMAL LOAD OF THE BRAKES}

Determination of the range of permitted thermal loads of the wet multidisc brakes by applying energy parameter $p v \mu$ (often efficiently applied to dry friction pairs) can not be applied since the intensity of cooling has a considerable influence on the friction process. For this reason, a parameter taken for the evaluation of energetic capability of the friction elements of multidisc brakes operating in oil is critical temperature of the friction surface as a function of the specific friction force. This dependence can be established on the basis of extensive investigations.

The amount of heat generated at a friction surface is function of the friction torque and relative sliding speed of the friction elements [6]. In the process of engagement of the brake these quantities are variable. Owing to this, the temperature of the friction surface, assuming all other conditions identical, is proportional to the amount of heat present at the friction surface, i.e. to the average power of sliding.

The investigations of friction pairs: metalloceramic based on copper-steel operating in oil, established that there was a limited range of permissible thermal loads [7]. Inside this range the metalloceramic friction elements have satisfactory operating lifetime and good resistance to wear.

The existence of the limit between the normal and enhanced wear is explained as follows [7]. When due to overload of an operating friction assembly its friction surfaces reach a high (limiting) temperature, thermal degradation of the oil between the friction surfaces may occur leading to a destruction of the minimum oil layer (destruction of the boundary lubrication). While the minimum oil layer exists, a high friction coefficient and a good cooling of the friction surfaces are achieved. Destruction of the minimum oil layer brings the friction assembly to the zone of semi-dry or dry friction which is accompanied by enhanced wear, even destruction of the friction assembly.

The experimental investigations of metalloceramic material MK-5 [7] showed that the speed of sliding, within a certain range, did not influence the qualitative picture of the process between friction surfaces. It was possible to establish the dependence in the form shown in Fig. 2, where: $\theta_{c r}$ is critical temperature of the friction surfaces, and $F_{\mu s}$ is specific friction force.

During these tests, it has also been established that the onset of the destruction of the oil layer was not dependent on the oil flow and 
distribution and size of the grooves on the friction surface, but on the normal force, temperature of the friction surface, oil properties, and type of the friction material. The permitted thermal loads of the friction elements of multidisc brakes operating in oil, for the specific friction forces $F_{\mu s}$, lie below curve $\theta_{c r}=f\left(F_{\mu s}\right)$. In this region the high reliability and good resistance to wear are accomplished.

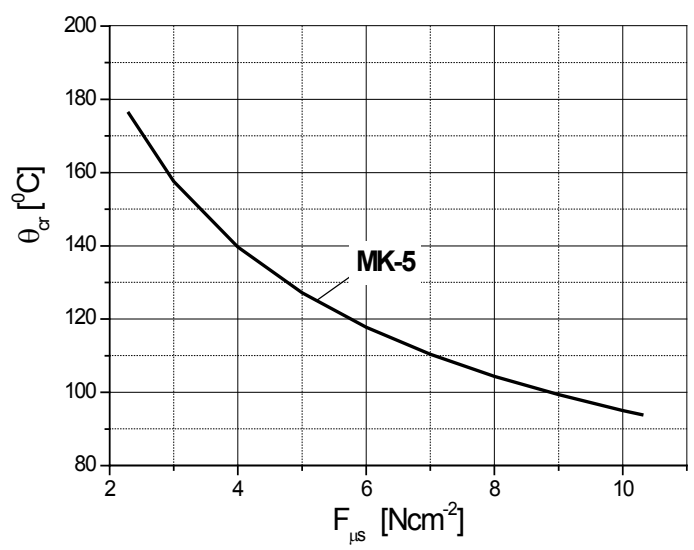

Fig. 2. Critical thermal load of metalloceramic friction discs

Dependence $\theta_{c r}=f\left(F_{\mu s}\right)$ can be represented by an empirical expression in the form [7]:

$$
\theta_{c r}=250 F_{\mu s}^{-0.42} \text {. }
$$

The dependence shown in Fig. 2 has been obtained experimentally on a test stand [7] by applying long-term braking under different loads. At each load, constant values of the friction torque and sliding speed have been maintained. The process of braking was running until the critical temperature resulting in destruction of the oil layer was reached which was accompanied by sudden growth of the friction torque.

The results presented in [7] have been the basis for establishing whether the sliding regimes of the examined multidisc brakes, $F_{4}$ and $F_{5}$, were within the limits of the permitted thermal loads. The limiting range of the working regimes where friction assemblies have preserved functionality and reliability has been identified. This is of particular importance for using these assemblies as service brakes since it requires a strict adherence to the instructions for use owing to their sensitivity to long-term braking and overload.

\section{THE TEST STAND}

Tests of the above brakes has been carried out on the test stand intended for complex testing of transmissions under load [8]. In the course of the tests, different operating regimes of the friction assemblies were simulated. This paper presents only the results concerning the regimes of braking with the engine disconnected.

For driving the test stand the same engine as the one used in the vehicle has been applied. Via a conical gear and a transfer case, the engine drives a planetary gearbox where the examined brakes have been integrated. For the purpose of simulating the conditions of a vehicle in exploitation, the test stand is supplied with a hydrodynamic brake, serving for achieving necessary loads, and with a flywheel, simulating one half of the kinetic energy of the vehicle, since the vehicle is provided with two planetary gearboxes and two final drives.

Before the service brake is activated, the engine is disconnected via the main clutch, and braking of the flywheel masses and other rotating parts is achieved by the service brake only. From the point of view of vehicle deceleration and thermal load of the friction assemblies this is the most unfavorable working regime.

Positions of brakes $F_{4}$ and $F_{5}$ within the kinematic scheme of the gearbox are presented in Fig. 3. Angular speeds $\omega_{4}$ and $\omega_{5}$ of rotating elements of the brakes and the corresponding loading torques $M_{4}$ and $M_{5}$ are determined from the measured braking torque $M_{i}$, speed of rotation of the output shaft of the gearbox $n_{i}\left(\omega_{i}\right)$, and the characteristics of the applied planetary set.

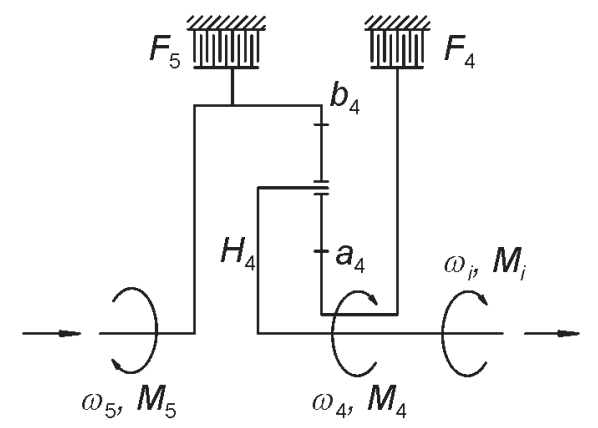

Fig. 3. Positions of the examined brakes in the scheme of the planetary gearbox 
During the tests the following measured quantities have been recorded [8] and [9], Table 2:

Table 2. Measured quantities during tests

\begin{tabular}{|c|c|c|}
\hline$M_{i}$ & {$[\mathrm{Nm}]$} & $\begin{array}{c}\text { Braking torque at the output } \\
\text { shaft of the gearbox }\end{array}$ \\
\hline$n_{w}, n_{i}$ & {$\left[\mathrm{~min}^{-1}\right]$} & $\begin{array}{c}\text { Speeds of rotation of the } \\
\text { input and output shafts of the } \\
\text { gearbox }\end{array}$ \\
\hline$p_{4}, p_{5}$ & {$[\mathrm{bar}]$} & $\begin{array}{c}\text { Activation pressures of brakes } \\
F_{4} \text { and } F_{5}\end{array}$ \\
\hline$\theta_{4}, \theta_{5}$ & {$\left[{ }^{\circ} \mathrm{C}\right]$} & $\begin{array}{c}\text { Temperatures of the friction } \\
\text { surfaces of brakes } F_{4} \text { and } F_{5}\end{array}$ \\
\hline
\end{tabular}

Measurement of friction surface temperatures was carried out on the immobile parts of the brakes by using thermocouples of type $\mathrm{K}$ and an HP 3497 Data Acquisition System, an HP 3456A Digital Voltmeter, an HP 9845 Desktop computer, and an HP-IB interface.

Fig. 4 shows a detail of the gearbox of one of the friction assemblies and position of the temperature sensor [10].

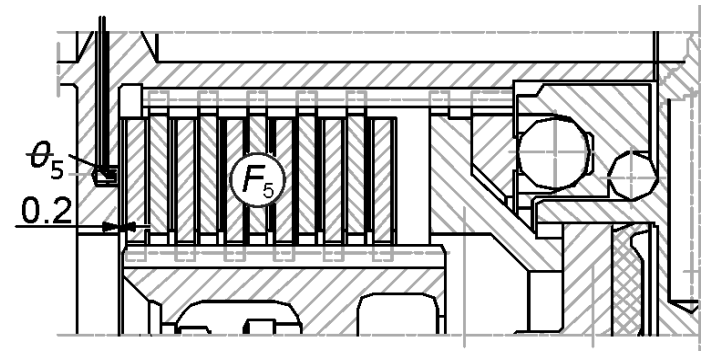

Fig. 4. Position of the temperature sensor

On the basis of the measured braking torque at the output of the gearbox $M_{i}$, and kinematic scheme of Fig. 3, torques $M_{4}$ and $M_{5}$ loading brakes $F_{4}$ and $F_{5}$ are determined. They also represent the corresponding friction torques $M_{t 4}$ and $M_{t 5}$.

$$
\begin{gathered}
M_{4}=M_{t 4}=M_{a 4}=\frac{M_{H 4}}{1+k_{4}}=0.341 \cdot M_{i}, \\
M_{5}=M_{5 t}=M_{b 4}=M_{a 4} \cdot k_{4}=0.659 \cdot M_{i},
\end{gathered}
$$

where $k_{4}=1.933$ is a characteristic of the planetary set, $a_{4}$ is sun gear of the planetary set, $H_{4}$ is carrier of planet gears and $b_{4}$ is epicycle (ring gear).
Angular speeds of the elements $F_{4}$ and $F_{5}$ are identical to angular speed $\omega_{i}$, since immediately prior to activation of the brakes, the gearbox was in the direct drive and all the elements shown in Fig. 3 were rotating at the same angular speed.

\section{THE EXPERIMENTAL RESULTS}

By bringing the engine speed to the regime corresponding to the maximum speed of the vehicle, braking in the fifth-direct drive has been simulated on the test stand.

A record of the measured quantities in the braking process made in one of the realized experiments is shown in Fig. 5.

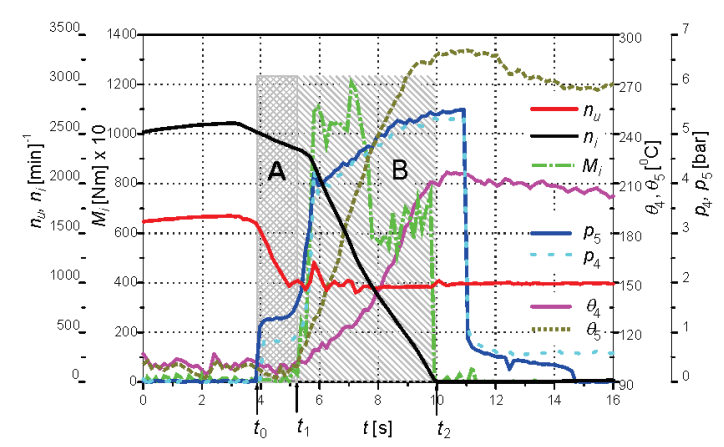

Fig. 5. A record of the measured quantities during braking process on the test stand

In Fig. 5 two characteristic regions can be identified:

Region A is the initial stage of the braking process, when brakes $F_{4}$ and $F_{5}$ are prepared for braking and chambers of the hydraulic cylinders are filled by oil (time interval $t_{0}-t_{1}$ ) and region $\mathrm{B}$ is the cycle of braking, occurring during time interval $\left(t_{1}-t_{2}\right)$, when an intensive sliding of the brakes is on. It is evident that owing to the sliding of the brakes, temperatures of the friction surfaces increase. After the flywheel mass is stopped (instant $t_{2}$ ) and somewhat delayed drop of the oil pressure, temperatures of brakes $F_{4}$ and $F_{5}$ are stabilized with a tendency of dropping due to the cooling action of the oil.

In order to determine the characteristic parameters of the sliding process during time interval $\left(t_{1}-t_{2}\right)$, processing the experimental 
data has been done by applying the following analytical expressions. [11]:

General expression for the friction torque

$$
M_{t}=F_{\mu} \cdot 2 \cdot R_{s} \cdot z=\mu \cdot F_{n} \cdot 2 \cdot R_{s} \cdot z,
$$

where $\mu$ is coefficient of friction, $F_{\mu}$ is force of friction, $F_{n}$ is normal force determined by expression:

$$
F_{n}=p \cdot A_{k}-F_{0},
$$

where $p$ is actuating pressure of the brake, and $F_{0}$ is force of return spring.

From the above relations it is possible to determine the specific friction force $\left(F_{\mu s}\right)$ and coefficient of friction $(\mu)$ in the form:

$$
\begin{gathered}
F_{\mu s}=\frac{M_{t}}{2 \cdot R_{s} \cdot z \cdot A_{l}}, \\
\mu=\frac{M_{t}}{2 \cdot R_{s} \cdot F_{n} \cdot z} .
\end{gathered}
$$

From the friction torque and angular speeds of the elements of the brakes it is possible to determine the work of sliding $\left(L_{k}\right)$ and power of sliding $\left(P_{k}\right)$ by the following expressions [11]:

$$
L_{k}=\int_{0}^{t_{k}} P_{k}(t) \cdot d t=\int_{0}^{t_{k}} M_{t}(t) \cdot \omega(t) \cdot d t,
$$

and

$$
P_{k}=M_{t} \cdot \omega,
$$

where $\omega$ is relative angular speed of rotating elements of brakes $F_{4}$ and $F_{5}$, and $t_{k}$ is sliding time of the brakes.

The friction torque and the power of sliding of brakes $F_{4}$ and $F_{5}$, shown in Figs. 6 and 7, are determined by Eqs. (2), (3) and (9).

By using Eqs. (6), (7) and (8), values of the specific friction forces, coefficients of friction, and sliding works in these experiments have been determined. The values are shown in Table 3, together with the measured temperature values.

Since the boundary shown in Fig. 2 is applicable in this case, the critical operating temperatures for both brakes have been identified from the specific friction forces, Table 3.
As regards the method of temperature measurement, it may be the subject of discussion whether the measured and true temperature values of the friction assembly coincide.

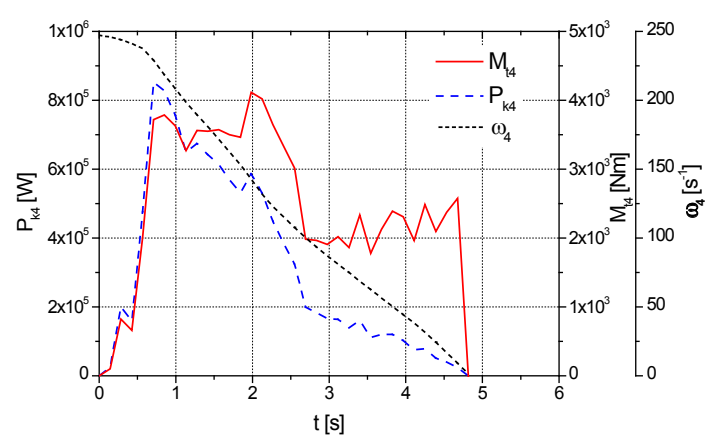

Fig. 6. Parameters of the sliding process of brake $F_{4}$

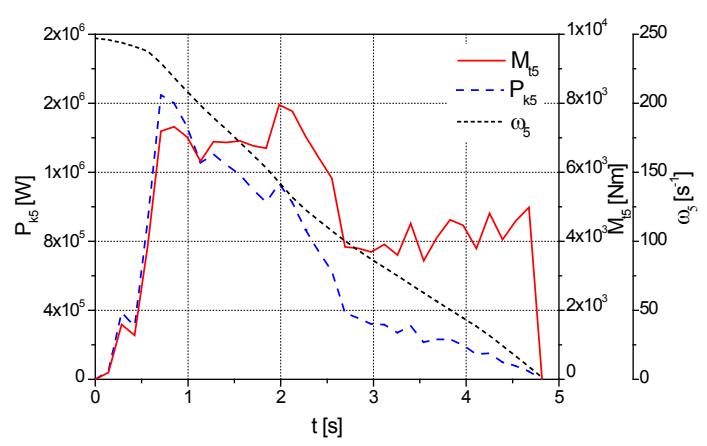

Fig. 7. Parameters of the sliding process of brake $F_{5}$

Table 3. Characteristic parameters of the braking process

\begin{tabular}{|c|c|c|c|}
\hline \multirow{2}{*}{ Characteristic parameters } & \multicolumn{2}{|c|}{ Brake } \\
\cline { 3 - 4 } & $F_{4}$ & $F_{5}$ \\
\hline$\mu$ & {$[-]$} & 0.039 & 0.056 \\
\hline$L_{k}$ & {$[\mathrm{MJ}]$} & 1.5566 & 3.0096 \\
\hline$F_{\mu s}$ & {$\left[\mathrm{~N} / \mathrm{cm}^{2}\right]$} & 2.35 & 3.79 \\
\hline$\theta_{c r}$ (from Fig. 2) & {$\left[{ }^{\circ} \mathrm{C}\right]$} & 175 & 143 \\
\hline $\begin{array}{c}\Delta \theta \\
\text { (from experiment) }\end{array}$ & {$\left[{ }^{\circ} \mathrm{C}\right]$} & 109 & 187 \\
\hline $\begin{array}{c}\theta_{\max } \\
\text { (from experiment) }\end{array}$ & {$\left[{ }^{\circ} \mathrm{C}\right]$} & 210 & 288 \\
\hline
\end{tabular}

In many cases temperature at the edge of the friction assembly is considerably lower compared to the temperature in the middle of the disc package. However, some investigations 
[12] showed that the difference between these temperatures was very small if the discs were made of sintered bronze. This is explained by good conductivity of sintered bronze.

In this work the assumption is made that thermal conductivity [13] of the disc package was relatively high since the percentage of copper in the sintered discs was prevailing. Therefore, for the purpose of the present analysis it was assumed that the measured temperature was equal to the true temperature of the friction assembly.

\section{ANALYSIS OF THE RESULTS}

From Table 3 it can be seen that the measured temperature at the friction surface of brake $F_{4}$ was $210{ }^{\circ} \mathrm{C}$, i.e. above the critical temperature $\left(175^{\circ} \mathrm{C}\right)$ which corresponds to the specific friction force of $2.35 \mathrm{~N} / \mathrm{cm}^{2}$ (Fig. 2). This shows that brake $F_{4}$ was operating in the region of impermissible loads.

In addition, the measured temperature at the friction surface of brake $F_{5}$ was $288{ }^{\circ} \mathrm{C}$ i.e. considerably above the critical temperature $\left(143{ }^{\circ} \mathrm{C}\right)$ which corresponds to the specific friction force of $3.79 \mathrm{~N} / \mathrm{cm}^{2}$ (Fig. 2). This case shows that brake $F_{5}$ was operating in the range of an exceptional overload. It can be concluded that the regime of friction in both cases caused thermal overload of the friction elements.

Visual inspection of the brakes, which followed after a certain number of braking cycles, showed considerable deformations of the elements of both brakes. Fig. 8 presents a photo of the package of the steel and metalloceramic discs showing clearly visible conical deformations, more apparent on the sintered discs. Greater defects were observed in brake $F_{5}$, which is logical owing to its greater thermal overload.

Fig. 9 shows surface of a steel disc which shows traces of partial burnings of the friction surface and deposits of the sintered material owing to an intensive wear.

Values of the coefficients of friction, Table 3 , are coincident with the values of the coefficients of friction obtained by the manufacturer while testing identical friction discs on an inertial test stand [14].

It is evident that the braking regime did not comply with the energetic capabilities of the friction elements, which lead to damaging of their working surfaces. It turned out that thermal load of the brakes caused by long-term slidings was considerably above their limiting values of the specific friction forces. The presented results show that the limiting values of thermal loads of the examined friction pairs can be efficiently used for determination of the optimum working regimes of multidisc brakes, even during design phase.

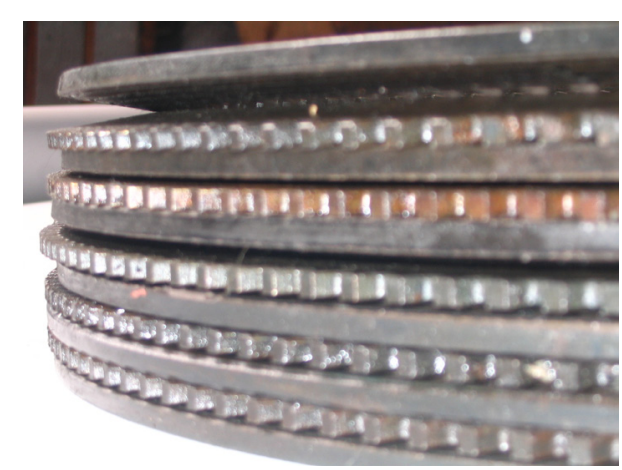

Fig. 8. Deformed package of discs of brake $F_{5}$ after tests

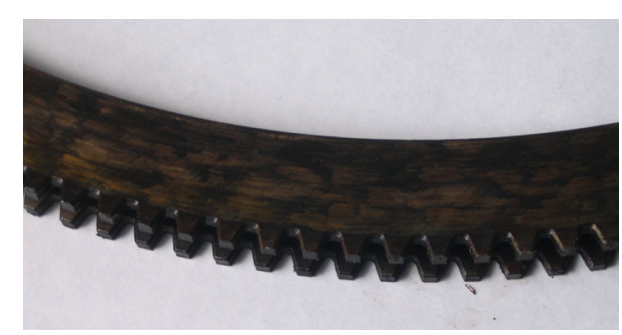

Fig. 9. Traces of the damage on a steel disc after tests

By applying the results obtained on the test stand to braking of a real vehicle, the measured temperatures of friction surfaces of the brakes can be presented as a function of the vehicle speed, Fig. 10. The vehicle speed is determined by expression:

$$
v=\frac{\omega_{i} \cdot r_{p t}}{i_{b p}},
$$

where $r_{p t}=0.333 \mathrm{~m}$ is average radius of the driving wheel and $i_{b p}=5.0$ is gear ratio of the final drive.

Fig. 10 shows that for the simulated braking regime, owing to relatively low limiting 
temperature values, braking of the vehicle from maximum speeds to a halt is not possible without damaging brakes $F_{4}$ and $F_{5}$. Nevertheless, braking from the maximum speed of the vehicle without damaging these brakes can be performed until speed drops to $48 \mathrm{~km} / \mathrm{h}$. If further braking is required, the transmission ratio has to be reduced or braking should be performed combined with short interruptions in order to ensure the corresponding cooling and thermal relief of the friction elements. These are extreme situations not recommendable in exploitation of a vehicle.

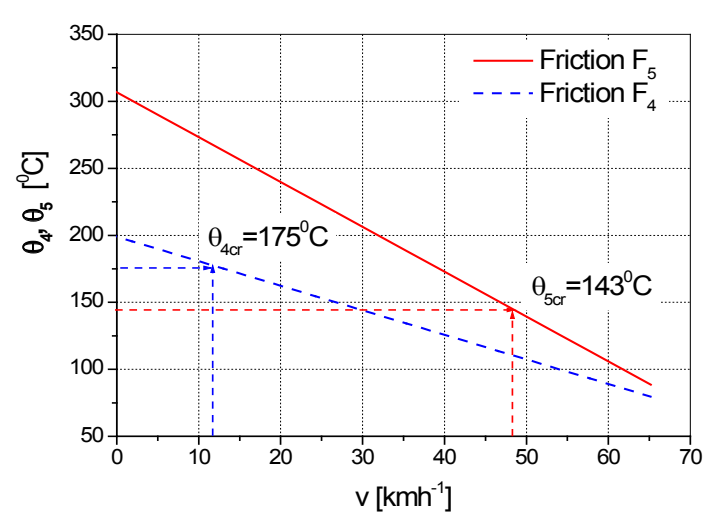

Fig. 10. The limiting braking conditions at maximum speeds

The instructions for using a vehicle say that braking of the vehicle by the braking pedal at high speeds should be avoided, since thermal overload of the friction elements and an enhanced wear are likely. In such situations only short braking is permitted, i.e. occasional activation of the brakes by special pneumatic command, i.e. when long-term braking is disabled.

These investigations confirm that multidisc brakes are sensitive to long-term slidings. They give a specific guidance to the driver for performing braking at higher vehicle speeds.

\section{CONCLUSIONS}

The performed tests show that the simulated regimes of braking did not comply with the energetic capabilities of the considered brakes. A long-term sliding, followed by high values of the sliding wor, caused high temperatures of the friction surfaces, which lead to the permanent damage of the brakes.

The accomplished specific friction forces indicated that the brakes were operated in the regions well above the limiting values of the permissible thermal loads, recommended for the material of the friction discs.

Conditions of the brakes, after a certain number of braking cycles, were in agreement with the previously stated conclusions. A visual inspection of the brakes showed significant deformations of the friction discs and traces of high temperatures at the friction surfaces.

These investigations allow defining the limiting regimes, i.e. the regimes when braking of a vehicle performed within the zone of maximum speeds does not cause permanent damage of the brakes. This is a practical contribution of the present work. The investigations also confirmed that these brakes were sensitive to long-term slidings, therefore these braking regimes should be avoided.

\section{REFERENCES}

[1] Derkacheva, G.M. (2000). Effects of preparation technique for MK-5 material on frictional and wear response. Powder Metallurgy and Metal Ceramics, vol. 39, no. 1-2, p. 38-40, DOI:10.1007/BF02677439.

[2] Gapojan, D.T. (1966). Friction clutches of automatic gearboxes, Mashinostroenye, Moscow. (in Russian)

[3] Živanović, Z., Janićijević, N. (1999). Automatic transmissions of motor vehicles. IP Ecolibri, Belgrade, p. 110-200. (in Serbian)

[4] Živanović, Z., Uskoković, A. (2000). The influence of the resistence to wear and sliding regimes of metalloceramic friction assemblies on their operating life cycle. Proceedings of XIth International Symposium "Motor Vehicles and Motors", Kragujevac, p. 137-140. (in Serbian)

[5] Živanović, Z. (1998). Energetic load of metalloceramic friction elements of a multidisc wet friction brake. Proceedings of $X^{\text {th }}$ International Symposium "Motor Vehicles and Motors”, Kragujevac, p. 107110. (in Serbian) 
[6] Zuckov, M.G., Fantalov, V.S. (1983). Wear out and friction coefficient of friction assemblies operating with metalloceramic disks in oil. Courier of Mechanical Engineering, no. 4, p. 25-26. (in Russian)

[7] Sopkin, V.A., Brikov, A.C. (1985). Testing the capacities of the multiple friction disks of oil cooled brakes. Tractors and Propulsion Machines, no. 3, p. 10-15. (in Russian)

[8] Milić, M., Pantić, M., Živanović, Z. (2007). Thermal load of multidisc friction assemblies in the braking process. Proceedings of the Symposium on Defense Technologies "OTEH 2007", p. 11-14. (in Serbian)

[9] Živanovic, Z. (2011). The development of an electro-hydraulic transmission control system of a high-speed tracked vehicle. International Journal of Heavy Vehicle Systems, vol. 18, no. 1, p. 46-63, DOI:10.1504/IJHVS.2011.037959.

[10] Todorovic, J. (1986). Testing of motor vehicles. Faculty of Mechanical Engineering, Belgrade. (in Serbian)
[11] Živanovic, Z. (1997). Thermal load of multiple friction clutches immersed in oil in process of gear change control. Mobility \& Vehicle Mechanics, Engines and Transportation Systems, vol. 23, no. 1, p. 1824.

[12] Marklund, P., Larsson, R. (2007). Wet clutch under limited slip conditionssimplified testing and simulation. Proceedings of the Institution of Mechanical Engineers, Part J: Journal of Engineering Tribology, vol. 221, no. 1, p. 545-551, DOI:10.1243/13506501JET252.

[13] Reibenschuh, M., Oder, G., Čuš, F., Potrč, I. (2009). Modelling and analysis of thermal and stress loads in train disc brakes - braking from $250 \mathrm{~km} / \mathrm{h}$ to standstill. Strojniški vestnik - Journal of Mechanical Engineering, vol. 55, no. 7-8, p. 494-502.

[14] Lazarević, D., Živanović, Z. (2003). Thermal stresses of motor vehicle clutches and brakes friction discs. Scientific Technical Review, vol. LIII, no. 4, p. 10-18. 